\title{
A Phenomenological Thermal-Mechanical Viscoelastic Constitutive Modeling for Polypropylene Wood Composites
}

\author{
Xiongqi Peng, Hongling Yin, Jun Chen, and Xue Liu \\ School of Materials Science and Engineering, Shanghai Jiao Tong University, 1954 Huashan Road, Shanghai 200030, China \\ Correspondence should be addressed to Xiongqi Peng, xqpeng@sjtu.edu.cn
}

Received 8 June 2012; Accepted 14 September 2012

Academic Editor: Roham Rafiee

Copyright () 2012 Xiongqi Peng et al. This is an open access article distributed under the Creative Commons Attribution License, which permits unrestricted use, distribution, and reproduction in any medium, provided the original work is properly cited.

This paper presents a phenomenological thermal-mechanical viscoelastic constitutive modeling for polypropylene wood composites. Polypropylene (PP) wood composite specimens are compressed at strain rates from $10^{-4}$ to $10^{-2} \mathrm{~s}^{-1}$ and at temperature of $90^{\circ} \mathrm{C}, 130^{\circ} \mathrm{C}$, and $170^{\circ} \mathrm{C}$, respectively. The mechanical responses are shown to be sensitive both to strain rate and to temperature. Based on the Maxwell viscoelastic model, a nonlinear thermal-mechanical viscoelastic constitutive model is developed for the PP wood composite by decoupling the effect of temperature with that of the strain rate. Corresponding viscoelastic parameters are obtained through curve fitting with experimental data. Then the model is used to simulate thermal compression of the PP wood composite. The predicted theoretical results coincide quite well with experimental data. The proposed constitutive model is then applied to the thermoforming simulation of an automobile interior part with the PP wood composites.

\section{Introduction}

Wood plastic composites (WPCs) are a new class of composite materials which combine the characteristics of plastic and wood fibers. In appearance, WPC sheets are similar to wood sheets, but the low stiffness of plastics makes the modulus of composites significantly lower than that of solid woods, and thus brings in a greatly improved formability. This makes it feasible to form WPC sheets into products with complex curvatures. WPCs have many additional advantages such as low cost, lightweight, and renewability. The increasing environmental concern has created enormous opportunities for introducing this kind of nature fiber plastic composites into high-volume consumer products such as automobiles, especially for car interior parts [1-4].

Nowadays, automobile interior parts made from WPCs are primarily manufactured by the process of thermoforming which is well suited for mass production with a cost-effective way. In thermoforming processes, stress relaxation and viscoelastic properties [5-8] of WPCs are very important. Temperature and pressure conditions in the forming process should be determined carefully taking into account the thermoviscoelastic property of WPCs. High temperature (about $170^{\circ} \mathrm{C}$ ) makes wood plastic composites show a strong nonlinear viscoelastic material behavior during forming. Under an inadequate forming condition, WPC specimen may be damaged or a high residual stress may present in the final formed parts. Besides, inappropriate processing parameters may incur quality problems such as serious thinning and insufficient filling defects. Many research efforts have been devoted to understanding the WPC thermoforming mechanism for solving process problems and optimum forming process design, either by experiment approaches $[9,10]$ or with numerical simulation techniques [11-16].

Thermoforming of WPCs is a thermal-mechanical coupled process which involves complex phenomenon such as nonlinear material behavior with large deformation, heat transfer, viscosity, and flow. Numerical simulations of WPC thermoforming process could provide a powerful tool for materials selection, tool design, and process optimization. Material models for WPCs constitute the cornerstone for numerical simulation of WPC thermoforming process. To obtain an accurate and meaningful simulation result, it is crucial to have an appropriate material model for WPCs, which is capable of reflecting the material behavior of WPCs rendering in thermoforming. By using cellular solid theories, Wolcott et al. [17] characterized the nonlinear compression behavior of wood composites under various temperature 

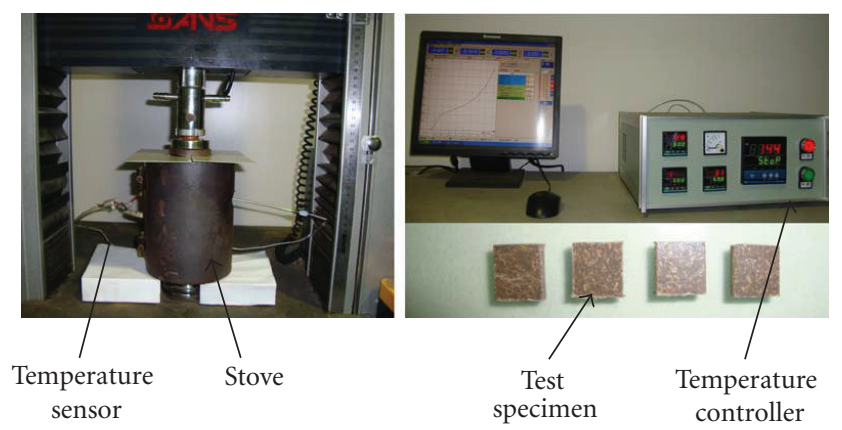

Figure 1: Thermo-compression test for PP wood composites.

and moisture contents. Oudjehane et al. [18] developed an analytical nonlinear continuum mechanics based model for predicting the consolidation of wood flake mats taking into account the effect of sheet thickness and press closing rate. By combining the homogenization method and a network mechanics model, Stålne and Gustafsson [19] proposed a three-dimensional model for characterizing the stiffness and hygroexpansion of fiber composite materials. Pooler and Smith [20] carried out a series of creep and recovery tests on High Density Polyethylene (HDPE) wood composites and then used a Prony series to describe the nonlinear viscoelastic of the wood-plastic composites. Damage effects were taken into account by using an effective stress. Bogren et al. [21] measured the dynamic stress transfer between fiber reinforcement and matrix ground materials to investigate the influence of fiber-matrix interface properties on the macroscopic mechanical properties of wood-fiber reinforced polylactide. A viscoelastic micromechanical model based on perfect interfacial stress transfer was taken for a comparison. Pramanick and Sain [22] developed a generic creep prediction model to describe the nonlinear viscoelastic behavior of HDPE wood composites. Erchiqui et al. [23] used a thermodynamical approach to express external work in terms of enclosed gas volume to investigate the effect of latter on the mechanical properties on wood-plastic composites. The Lodge model was selected for characterizing the viscoelastic behavior.

In this study, the thermoviscoelasticity of PP wood composites is characterized by unidirectional thermocompression tests with various strain rates from $10^{-4}$ to $10^{-2} \mathrm{~s}^{-1}$ and under temperature $90^{\circ} \mathrm{C}, 130^{\circ} \mathrm{C}$, and $170^{\circ} \mathrm{C}$, respectively. A nonlinear thermomechanical viscoelastic constitutive model for PP wood fiber composite is developed with a phenomenological approach by using the Maxwell model. The effect of temperature is decoupled with that of the strain rate to greatly facilitate the material characterization process for the PP wood composite. Corresponding viscoelastic parameters of the PP wood composite are obtained through curve fitting with experimental results. Model validation is implemented by comparing numerical stresses with experimental data. The developed thermomechanical viscoelastic constitutive model is then applied to the thermoforming simulation of an automobile interior part with the PP wood fiber composite.

\section{Thermocompression Test and Results}

The compression test is set up according to the ASTM D6641(M) standard. A PP wood fiber composite sheet with thickness of $2.57 \mathrm{~mm}$ is cut into $10 \mathrm{~mm} \times 10 \mathrm{~mm}$ specimens. A CMT4000 series electronic universal testing machine with an oven and a digital temperature controller is used to carry out the unidirectional thermocompression tests for the PP wood fiber composite. Figure 1 shows the experimental setup along with some test samples. Since the thermoforming of the PP wood composites is performed above the glass transition temperature $\left(T_{g}\right)$ of $\mathrm{PP}$ which is about $80^{\circ} \mathrm{C}$, the compression tests are accordingly performed under different temperature $\left(90^{\circ} \mathrm{C}, 130^{\circ} \mathrm{C}\right.$, and $\left.170^{\circ} \mathrm{C}\right)$, which are all above the $T_{g}$ of PP, for the purpose of characterizing the mechanical behavior of the WPC during forming. Three different loading rates $(0.1 \mathrm{~mm} / \mathrm{min}, 0.5 \mathrm{~mm} / \mathrm{min}$, and $5 \mathrm{~mm} / \mathrm{min})$ are chosen according to two reasons. First, a very small rate $(0.1 \mathrm{~mm} / \mathrm{min})$ is chosen for a quasistatic test. The other two loading rates are set to reflect the effect of strain rates on the material response as well as to cover the forming speed range of the wood composite. The tests are approximated as constant strain rate. Four specimens are prepared for each temperature and loading rate combination case.

The load-displacement curves for each thermocompression test are recorded and then averaged and converted to true stress-strain curves. Figure 2 shows the true stressstrain curves under different temperature and different strain rate. The trends of the true stress-strain curves are similar. Initially, it exhibits linear elastic deformation in a small strain range. When the strain increases to some value, it exhibits nonlinear behavior. There is no apparent yield point in the whole thermocompression stress-strain curves.

The stress-strain curves in Figure 2 indicated that the mechanical responses of PP wood fiber composites are sensitive to strain rate and temperature as well. With the temperature increasing, the maximum stress decreases. In addition, increasing strain rate has an equivalent effect on the stress as reducing the temperature. Figure 2 also shows that the effect of temperature on the stress is more prominent than the strain rate.

\section{Viscoelastic Constitutive Model for PP Wood Composite}

In PP wood fiber composites, the PP resin matrix shows viscoelastic characteristics. Viscoelastic behavior in wood is not as prominent as it is in polymer. Hence, for simplification of determining model constants, it is assumed that wood fiber renders elastic properties. The Maxwell viscoelastic model is selected to characterize the comprehensive mechanical properties of the PP wood fiber composites. Figure 3 shows the schematic of the Maxwell viscoelastic model. In Figure $3, E_{0}, E_{1}$, and $\eta$ are the to-be-determined viscoelastic parameters.

In Figure 3, the stress of the spring is equal to that of the damper in the serial connection part. The total strain $\varepsilon$ in 


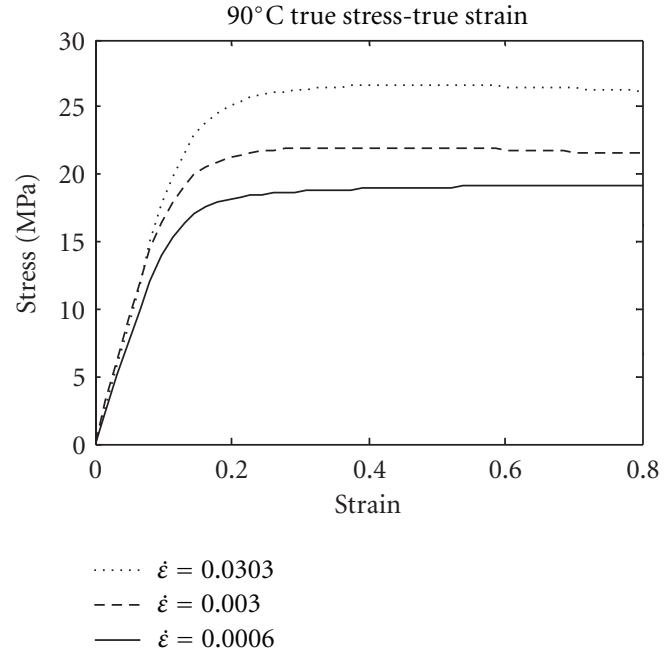

(a)

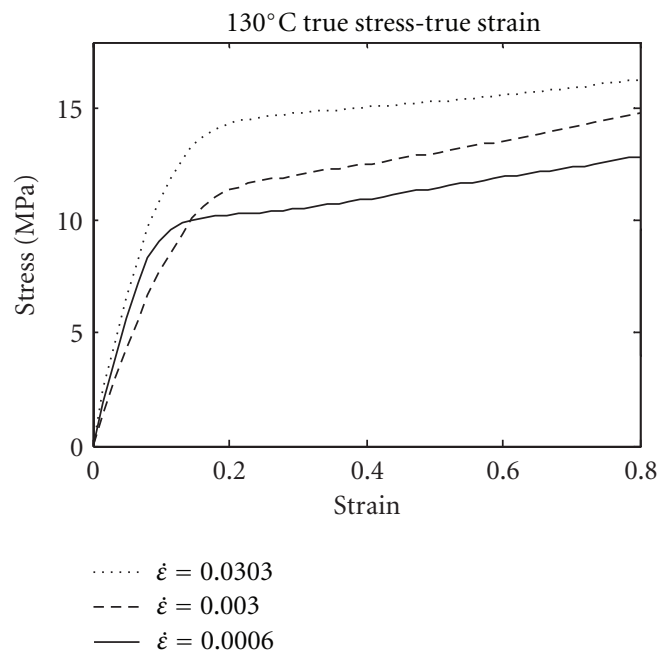

(b)

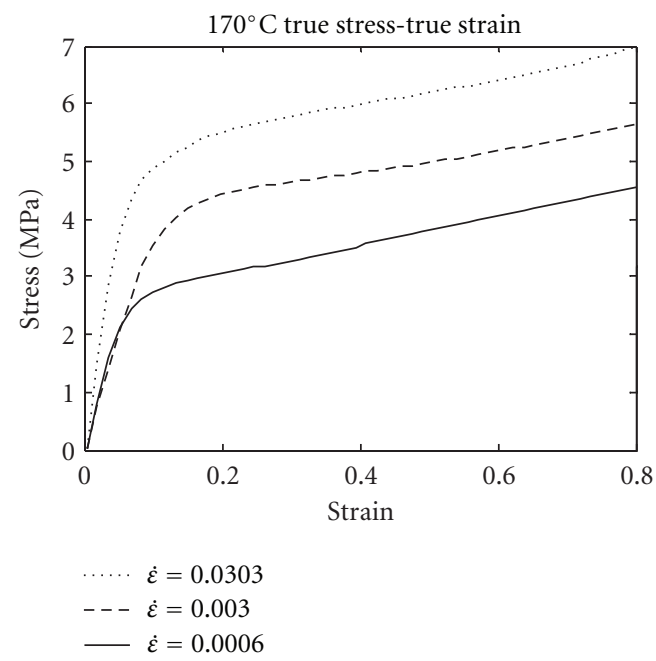

(c)

FIgURE 2: True stress-strain curves under compression with different strain rate $\left(\mathrm{s}^{-1}\right)$.

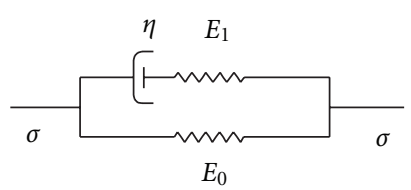

FIGURE 3: The generalized Maxwell viscoelastic model for PP wood composites.

the serial connection part is the summation of the spring strain $\varepsilon_{1}$ and the damper strain $\varepsilon_{2}$, that is,

$$
\begin{gathered}
\varepsilon=\varepsilon_{1}+\varepsilon_{2}, \\
\dot{\varepsilon}=\frac{\dot{\sigma}_{1}}{E_{1}}+\frac{\sigma_{1}}{\eta},
\end{gathered}
$$

where $E_{1}$ is the equivalent Young's modulus of PP with a unit of $\mathrm{Pa}, \eta$ is a viscosity with a unit of $\mathrm{N}-\mathrm{s} / \mathrm{m}^{2}$. Combining (1) leads to

$$
\dot{\sigma}_{1}+\frac{\sigma_{1}}{\theta}=E_{1} \dot{\varepsilon}
$$

where $\theta=\eta / E_{1}$ is the relaxation time of the PP wood composite. The stress $\sigma_{1}$ can be obtained by convolution integral as

$$
\sigma_{1}=\int_{-\infty}^{t} E_{1} \exp \left(-\frac{t-\tau}{\theta}\right) \dot{\varepsilon}(\tau) d \tau
$$

In large deformation, the stress $\sigma_{2}$ of the spring in the parallel part is usually nonlinear. Based on the pattern of the stressstrain curves shown in Figure 2, $\sigma_{2}$ can be expressed in an exponential format as

$$
\sigma_{2}=E_{0} \varepsilon^{n}
$$




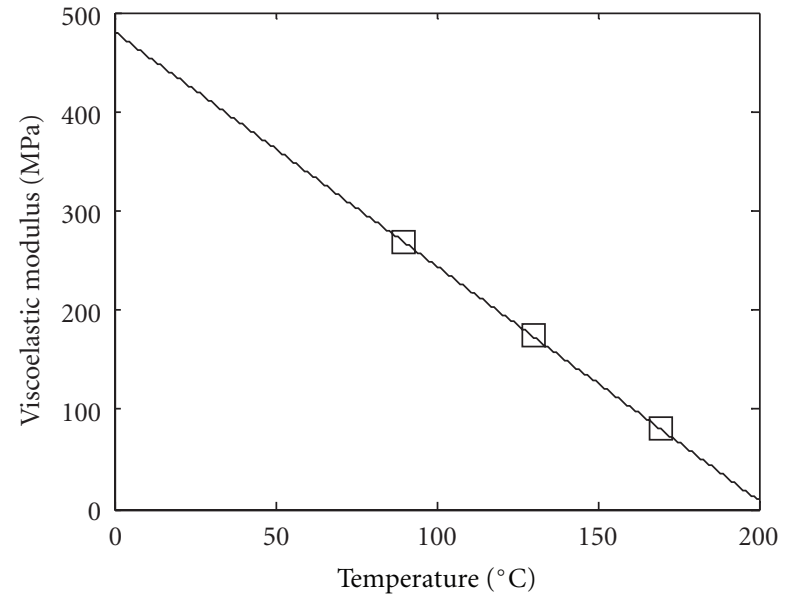

FIGURE 4: Relations between viscoelastic modulus $E_{1}$ and temperature.

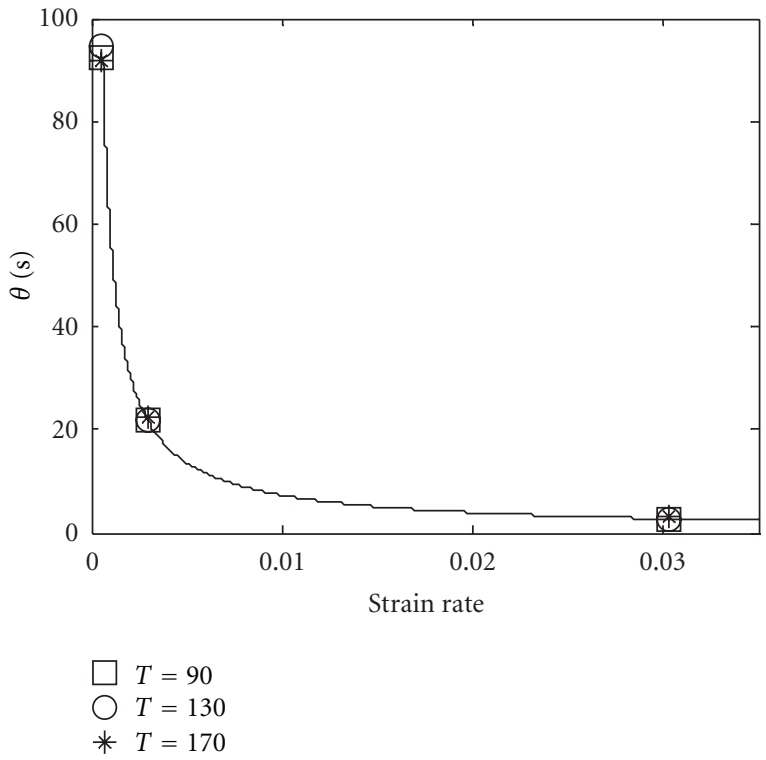

Figure 5: Relations between relaxation time $\theta$ and strain rate.

where $E_{0}$ is the Young's modulus of the wood fiber with a unit of $\mathrm{Pa}, n$ is a material constant. The total stress of the model is then the summation of $\sigma_{1}$ and $\sigma_{2}$

$$
\sigma=E_{0} \varepsilon^{n}+\int_{-\infty}^{t} E_{1} \exp \left(-\frac{t-\tau}{\theta}\right) \dot{\varepsilon}(\tau) d \tau
$$

where $\dot{\varepsilon}$ stands for strain rate. Experimental studies [24, $25]$ on wood fiber behavior indicated that the mechanical properties of wood fiber have insignificant variation under different temperature and testing rate. Hence, it is assumed that the elastic response of the wood fiber $\left(\sigma_{2}\right)$ is independent of temperature and strain rate, and the elastic behavior of the $\mathrm{PP}$ resin (the spring in the serial connection part) is affected by temperature only. As a result, the elastic parameters $E_{0}$ and $n$ are constants independent of temperature and strain rate, and the parameter $E_{1}$ is a function of temperature only.

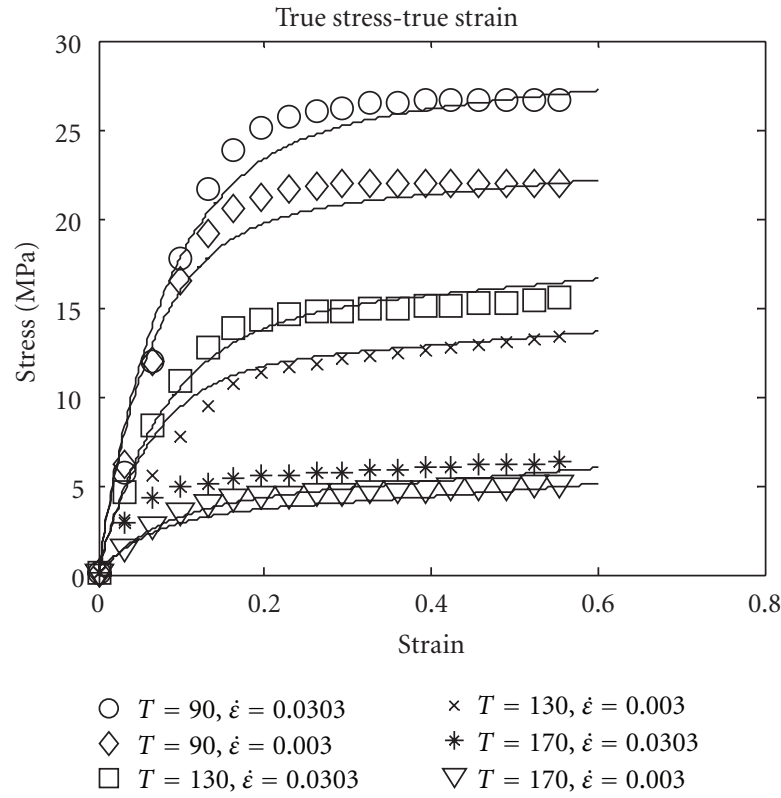

FIgURE 6: Comparison of numerical stress of thermocompression tests with experimental data.

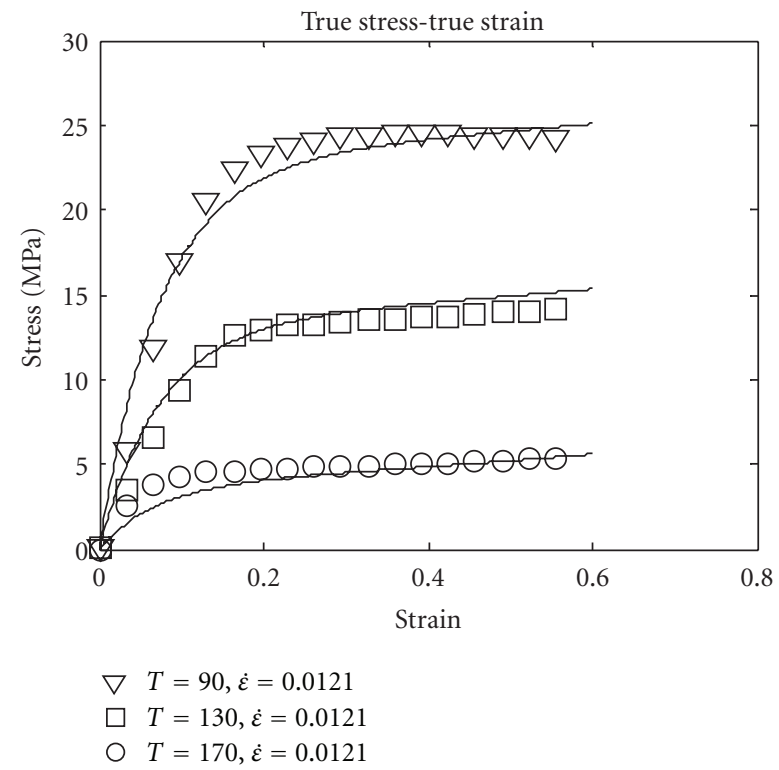

FIGURE 7: Comparison of simulation results with experimental data at strain rate 0.0121 .

Taking advantage of these assumptions and simplifications and implementing least square fitting on each individual experimental stress-strain curve, the material parameters in the proposed nonlinear thermal-mechanical viscoelastic constitutive model for the PP wood composite can be obtained. The elastic material constants $E_{0}$ and $n$ are

$$
E_{0}=3.37 \mathrm{MPa}, \quad n=1.73 .
$$

Other material parameters are listed in Table 1. 
TABLE 1: Viscoelastic parameters of PP wood composites under different temperature.

\begin{tabular}{|c|c|c|c|c|c|c|}
\hline \multirow{2}{*}{$\dot{\varepsilon}\left(\mathrm{s}^{-1}\right)$} & \multicolumn{2}{|c|}{$90^{\circ} \mathrm{C}$} & \multicolumn{2}{|c|}{$130^{\circ} \mathrm{C}$} & \multicolumn{2}{|c|}{$170^{\circ} \mathrm{C}$} \\
\hline & $E_{1} / \mathrm{MPa}$ & $\theta / \mathrm{s}$ & $E_{1} / \mathrm{MPa}$ & $\theta / \mathrm{s}$ & $E_{1} / \mathrm{MPa}$ & $\theta / \mathrm{s}$ \\
\hline 0.0006 & & 92.42 & & 94.66 & & 91.5 \\
\hline 0.0030 & 320.1 & 21.63 & 183.1 & 21.67 & 58.5 & 22.56 \\
\hline 0.0303 & & 2.66 & & 2.63 & & 3 \\
\hline
\end{tabular}

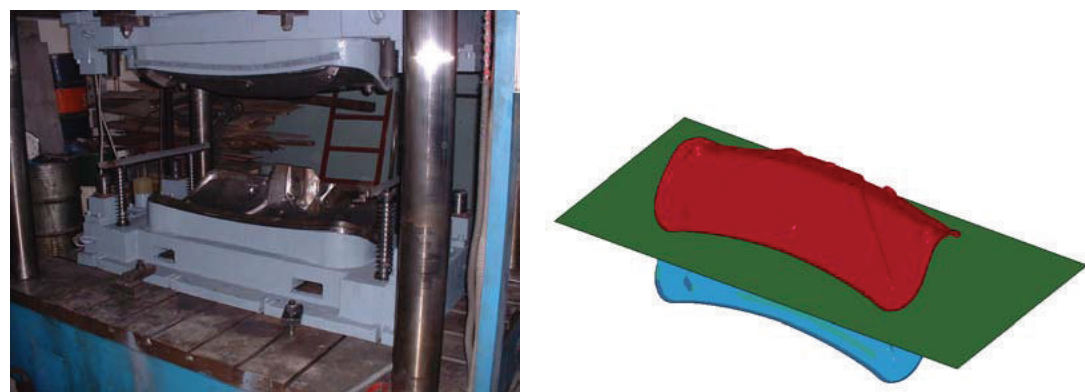

Figure 8: Thermal forming setup.

As shown in Figure 4, the viscoelastic modulus $E_{1}$ linearly changes with temperature for the testing temperature levels, which cover the forming temperature. Hence, $E_{1}(\mathrm{MPa})$ can be obtained by curve fitting as

$$
E_{1}=-3.27 T+612.3
$$

where $T$ denotes temperature with a unit of degrees of Celsius. The relaxation time $\theta$ under various strain rate and temperature is shown in Figure 5. As indicated by Table 1 and Figure 5, the relaxation time $\theta$ is insensitive to temperature and can be assumed as a function of strain rate only. By curving fitting in Figure 5, the relaxation time $\theta$ can be expressed as

$$
\theta=\frac{0.1138}{(\dot{\varepsilon})^{0.9044}}
$$

In summary, the nonlinear thermal-mechanical viscoelastic constitutive model for the PP wood composite can be expressed as

$$
\begin{aligned}
\sigma=3.37 \varepsilon^{1.73}+\int_{-\infty}^{t} & (-3.27 T+612.3) \\
& \times \exp \left(-\frac{(t-\tau)}{0.1138} \dot{\varepsilon}^{0.9044}\right) \dot{\varepsilon}(\tau) d \tau
\end{aligned}
$$

\section{Model Validation and Thermoforming Simulation}

The developed nonlinear thermoviscoelastic constitutive model for the PP wood composite is implemented as a UMAT in LS-Dyna. The previous thermocompression tests are simulated with the developed viscoelastic model. Figure 6 shows the comparison of the numerical stresses predicted from the viscoelastic model with corresponding experimental data for each test. In Figure 6, the solid lines denote numerical stresses and the discrete data points represent experimental stresses. As can be seen from Figure 6, in general, the numerical stresses are in a good agreement with experimental data, with an error less than $10 \%$.

To further validate the developed nonlinear thermoviscoelastic constitutive model, thermocompression tests are carried out under strain rate $0.012 \mathrm{~s}^{-1}$ with temperature $90^{\circ} \mathrm{C}, 130^{\circ} \mathrm{C}$, and $170^{\circ} \mathrm{C}$, respectively. Simulation results based on the developed constitutive model are compared with corresponding experimental data in Figure 7. The solid lines in Figure 7 represent numerical stresses and the discrete data points are experimental stresses under strain rate $0.012 \mathrm{~s}^{-1}$ with various temperature. As presented in Figure 7 , reasonable agreement is obtained in a sense of overall. It demonstrates that the proposed constitutive model can accurately and effectively characterize the nonlinear thermal-mechanical viscoelastic material behavior of the PP wood composite.

Finally, the thermoforming simulation of a car interior part of the PP WPC is implemented with the viscoelastic material model. The forming system and its FEM model are shown in Figure 8. Experimental study on thermoforming of the car interior part will be carried out in future work. The WPC composite sheet size is $1750 \mathrm{~mm} \times 810 \mathrm{~mm}$ with a thickness of $2.75 \mathrm{~mm}$. The sheet is heated up to a temperature above the glass transition temperature of PP, then pressed and cooled to room temperature to form the final part.

Figure 9 presents the thickness distribution contour of the formed part under an initial temperature of $130^{\circ} \mathrm{C}$. As shown in Figure 9, there is a significant thickness reduction at some locations with small features. The maximum thickness-reducing ratio reaches to about $70 \%$, which 


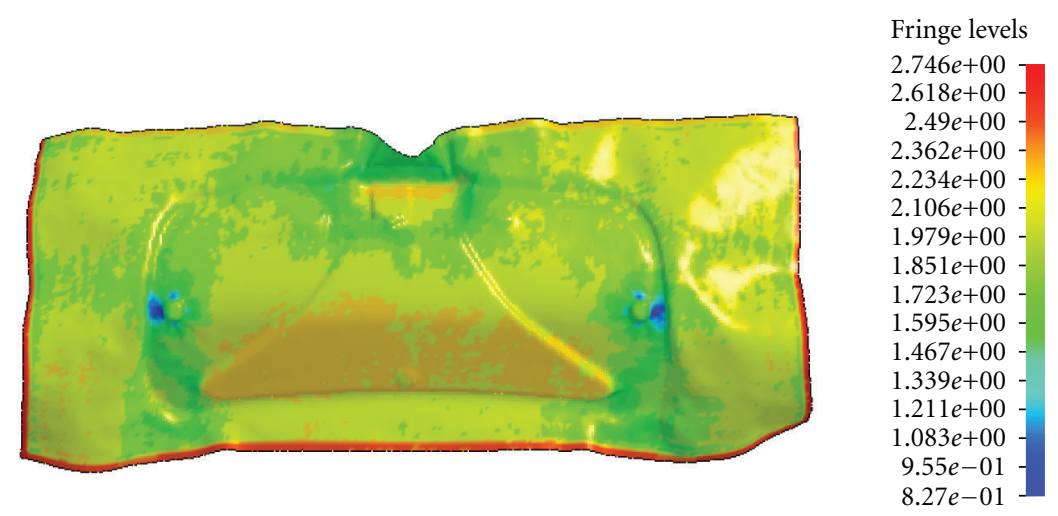

Figure 9: Thickness distribution with forming temperate of $130^{\circ} \mathrm{C}$.

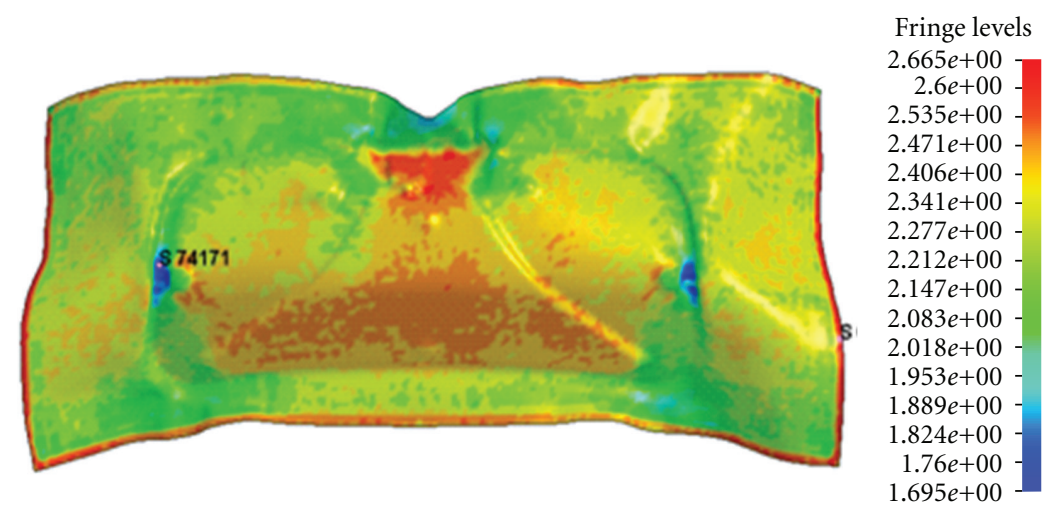

FIgURE 10: Thickness distribution with forming temperate of $170^{\circ} \mathrm{C}$.

will result in serious defects for the formed part. The thickness distribution contour of the formed part under an initial temperature of $170^{\circ} \mathrm{C}$ is shown in Figure 10 . The maximum thickness-reducing ratio improves to about $38 \%$. This demonstrates that the heating temperature is a critical processing parameter for the thermoforming of the PP wood composite sheet.

\section{Conclusions}

Based on thermocompression test results of PP wood fiber composites under different temperature and strain rate, a thermal-mechanical viscoelastic model is developed for the PP wood composite with a phenomenological approach by using the Maxwell model. The material parameters in the model are either simplified as constants or assumed to be temperature-related or strain-rate-related only. With those reasonable simplifications and assumptions, the effect of temperature is decoupled with that of the strain rate in the material modelling. This greatly facilitates the material characterizing process. The developed viscoelastic model is validated by comparing numerical results with experimental data under a strain rate differing from those used in the material characterizing process. This study provides a basis for the thermoforming simulation and processing design for the PP wood fiber composite.

\section{Acknowledgment}

The present research is funded by the China National Natural Science Foundation $(50975236,11172171)$.

\section{References}

[1] R. Kent, "Above board-wood-plastic composites," Materials World, vol. 13, no. 1, pp. 38-40, 2005.

[2] P. M. Smith and M. P. Wolcott, "Opportunities for wood/ natural fiber-plastic composites in residential and industrial applications," Forest Products Journal, vol. 56, no. 3, pp. 4-11, 2006.

[3] A. Ashori, "Wood-plastic composites as promising greencomposites for automotive industries!," Bioresource Technology, vol. 99, no. 11, pp. 4661-4667, 2008.

[4] H. Kinoshita, K. Kaizu, M. Fukuda, H. Tokunaga, K. Koga, and K. Ikeda, "Development of green composite consists of woodchips, bamboo fibers and biodegradable adhesive," Composites B, vol. 40, no. 7, pp. 607-612, 2009.

[5] Y. Wang, J. Z. Cao, and L. Z. Zhu, "Stress relaxation of wood flour/polypropylene composites at room temperature," Wood and Fiber Science, vol. 43, no. 3, pp. 262-270, 2011.

[6] M. P. Wolcott, F. A. Kamke, and D. A. Dillard, "Fundamentals of flakeboard manufacture: viscoelastic behavior of the wood component," Wood and Fiber Science, vol. 22, no. 4, pp. 345361,1990 . 
[7] C. Dai, "Viscoelasticity of wood composite mats during consolidation," Wood and Fiber Science, vol. 33, no. 3, pp. 353363, 2001.

[8] S. Tamrakar, R. A. Lopez-Anido, A. Kiziltas, and D. J. Gardner, "Time and temperature dependent response of a woodpolypropylene composite," Composites A, vol. 42, no. 7, pp. 834-842, 2011.

[9] D. Bhattacharyya, M. Bowis, and K. Jayaraman, "Thermoforming woodfibre-polypropylene composite sheets," Composites Science and Technology, vol. 63, no. 3-4, pp. 353-365, 2003.

[10] S. Migneault, A. Koubaa, F. Erchiqui, A. Chaala, K. Englund, and M. P. Wolcott, "Effects of processing method and fiber size on the structure and properties of wood-plastic composites," Composites A, vol. 40, no. 1, pp. 80-85, 2009.

[11] S. J. Liu, "Modeling and simulation of the vacuum forming of wood fiber-filled thermoplastic composites," Polymer Composites, vol. 18, no. 6, pp. 673-680, 1997.

[12] A. Oudjehane, F. Lam, and S. Avramidis, "Forming and pressing processes of random and oriented wood composite mats," Composites B, vol. 29, no. 3, pp. 211-215, 1998.

[13] H. Thoemen and P. E. Humphrey, "Modeling the continuous pressing process for wood-based composites," Wood and Fiber Science, vol. 35, no. 3, pp. 456-468, 2003.

[14] Y. Dong, R. J. T. Lin, and D. Bhattacharyya, "Finite element simulation on thermoforming acrylic sheets using dynamic explicit method," Polymers and Polymer Composites, vol. 14, no. 3, pp. 307-328, 2006.

[15] J. N. Lee, F. A. Kamke, and L. T. Watson, "Simulation of the hot-pressing of a multi-layered wood strand composite," Journal of Composite Materials, vol. 41, no. 7, pp. 879-904, 2007.

[16] F. Erchiqui, F. Godard, A. Gakwaya, A. Koubaa, M. Vincent, and H. Kaddami, "Engineering investigations on the potentiality of the thermoformability of HDPE charged by wood flours in the thermoforming part," Polymer Engineering and Science, vol. 49, no. 8, pp. 1594-1602, 2009.

[17] M. P. Wolcott, F. A. Kamke, and D. A. Dillard, "Fundamental aspects of wood deformation pertaining to manufacture of wood-based composites," Wood and Fiber Science, vol. 26, no. 4, pp. 496-511, 1994.

[18] A. Oudjehane, F. Lam, and S. Avramidis, "A continuum model of the interaction between manufacturing variables and consolidation of wood composite mats," Wood Science and Technology, vol. 32, no. 6, pp. 381-391, 1998.

[19] K. Stålne and P. J. Gustafsson, "Three-dimensional model for analysis of stiffness and hygroexpansion properties of fiber composite materials," Journal of Engineering Mechanics, vol. 128, no. 6, pp. 654-662, 2002.

[20] D. J. Pooler and L. V. Smith, "Nonlinear viscoelastic response of a wood-plastic composite including temperature effects," Journal of Thermoplastic Composite Materials, vol. 17, no. 5, pp. 427-445, 2004.

[21] K. M. Bogren, E. K. Gamstedt, R. C. Neagu et al., "Dynamicmechanical properties of wood-fiber reinforced polylactide: experimental characterization and micromechanical modeling," Journal of Thermoplastic Composite Materials, vol. 19, no. 6, pp. 613-637, 2006.

[22] A. Pramanick and M. Sain, "Nonlinear viscoelastic creep prediction of HDPE-agro-fiber composites," Journal of Composite Materials, vol. 40, no. 5, pp. 417-431, 2006.

[23] F. Erchiqui, F. Godard, A. Koubba, M. Vincent, and H. Kaddami, "Investigation of relaxation properties and potentiality of the thermoformability of HDPE charged by wood flours,"
Journal of Reinforced Plastics and Composites, vol. 28, no. 10, pp. 1153-1168, 2009.

[24] N. Chand, K. G. Satyanarayana, and P. K. Rohatgi, "Mechanical characteristics of sunhemp fibres," Indian Journal of Textile Research, vol. 11, no. 2, pp. 86-89, 1986.

[25] N. Chand and S. A. R. Hashmi, "Mechanical properties of sisal fibre at elevated temperatures," Journal of Materials Science, vol. 28, no. 24, pp. 6724-6728, 1993. 

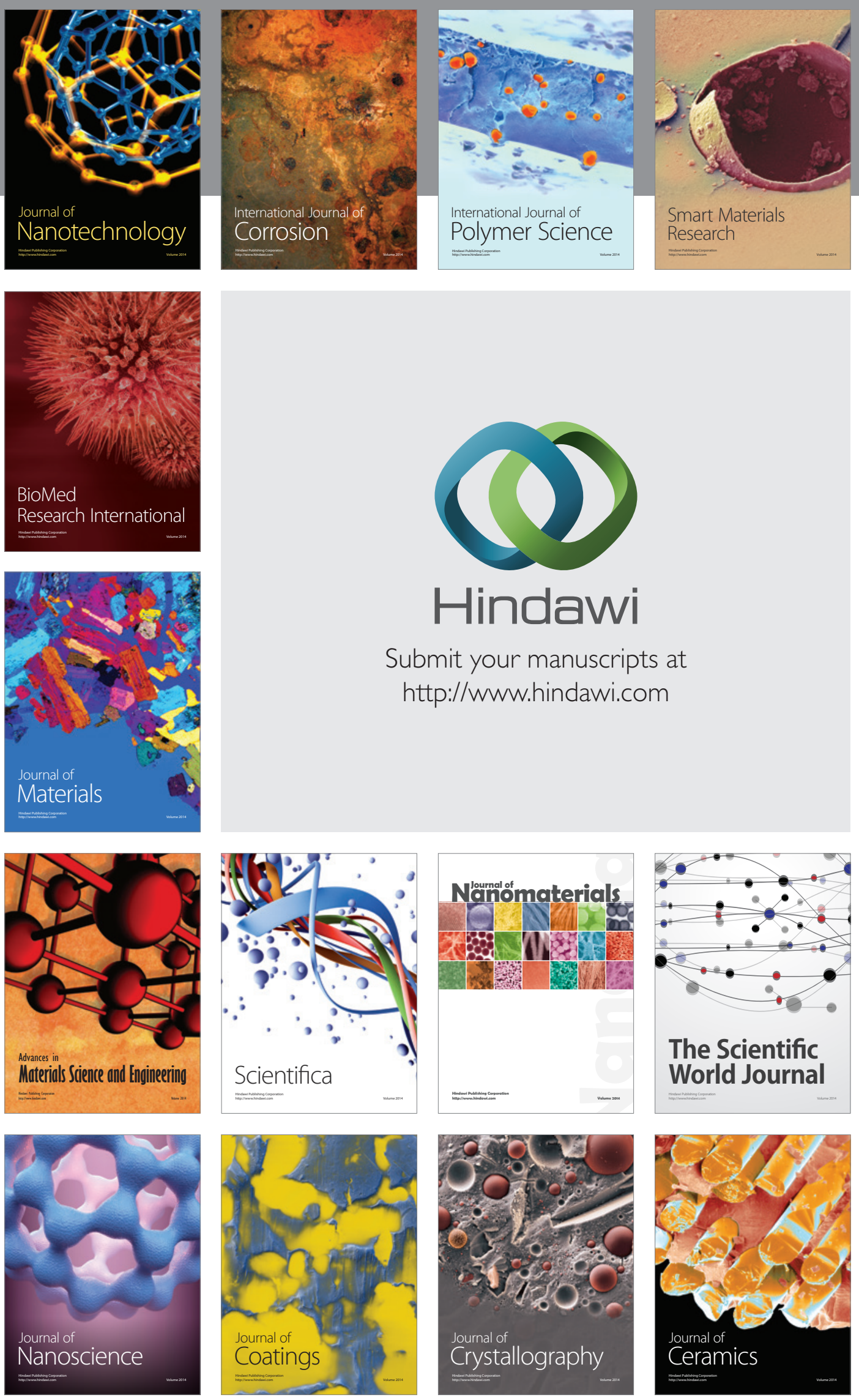

The Scientific World Journal

Submit your manuscripts at

http://www.hindawi.com

\section{World Journal}

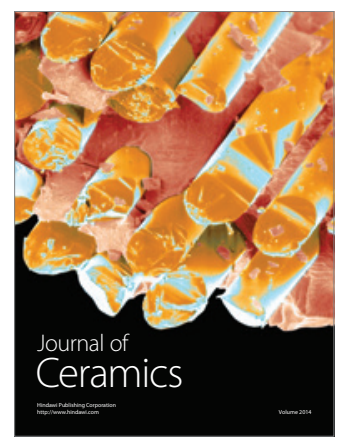

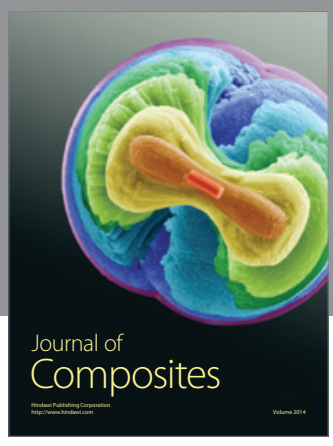
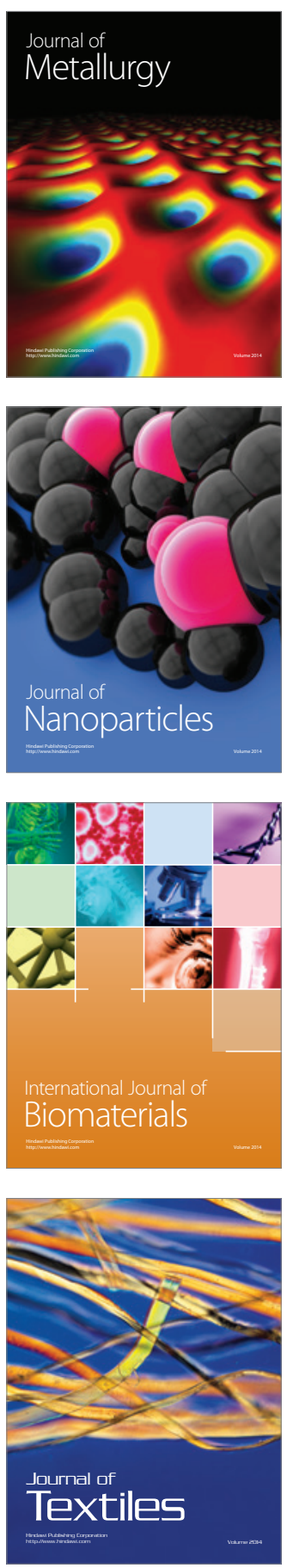